\section{Processos em Relacionamentos Interorganizacionais para Desenvolvimento de Capacidade de Absorção em Startups}

\author{
Processes in Interorganizational Relationships to Develop Absorptive Capacity \\ in Startups
}

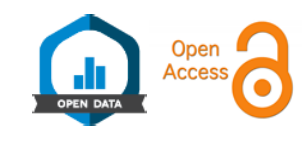

\author{
Alexandre Rodrigues Cajuela ${ }^{1}$ \\ Simone Vasconcelos Ribeiro Galina ${ }^{1}$
}

\section{RESUMO}

Objetivo: um dos fatores relacionados às capacidades dinâmicas é a capacidade de absorção e, até agora, trabalhos empíricos sobre capacidades foram conduzidos majoritariamente com empresas de grande porte e pouco se sabe sobre como ocorrem em startups. Nesse contexto, o objetivo deste trabalho é fornecer uma compreensão de como a capacidade de absorção ocorre em startups que mantêm relacionamentos interorganizacionais com grandes empresas. Método: a pesquisa utilizou um desenho qualitativo de estudo de casos múltiplos e a investigação de sete startups constituiu o corpus de estudo. Os dados foram analisados com uso de análise estatística, análise de conteúdo e análise de processos de negócio. Resultados: a inter-relação de startups com grandes empresas em programas de aceleração potencializa o desenvolvimento de capacidades para as startups, pois facilita o acesso e a assimilação de conhecimento. Já a transformação e exploração de conhecimento auxiliam a modificação da estrutura, de processos e de recursos das startups para atender à grande empresa, e o desenvolvimento de novos produtos e serviços para o mercado ocorre de forma modesta e incremental. Conclusões: o estudo evidencia como as ações formais dos programas de aceleração corporativa de grandes empresas contribuem para o desenvolvimento de capacidade de absorção em startups.

Palavras-chave: aceleradora corporativa; capacidade de absorção; capacidades dinâmicas; gerenciamento de processos de negócio; relacionamentos interorganizacionais.

Classificação JEL: L26, D24, N16.
1 Universidade de São Paulo, Faculdade de Economia, Administração e Contabilidade de Ribeirão Preto, Ribeirão Preto, SP, Brasil.

Como citar: Cajuela, A. R., \& Galina, S. V. R. (2020). Processes in interorganizational relationships to develop absorptive capacity in startups. Revista de Administração Contemporânea, 24(6), 550-566. https://doi.org/10.1590/1982-7849rac2020180329

\# de revisores convidados até a decisão:

\# de revisores convidados a
$1^{a}$ rodada
$2^{a}$ rodada
$3^{a}$ rodada
$4^{a}$ rodada

\section{ABSTRACT}

Objective: one of the factors related to dynamic capabilities is the absorptive capacity and until now, empirical work on capabilities has been conducted mainly with large companies and little is known about how they occur in startups. In this context, the aim of this work is to provide an understanding of how absorptive capacity occurs in startups, which maintains interorganizational relationships with large companies. Methods: the research used a qualitative multiple case study design and the investigation of seven startups constituted the study corpus. The data were analyzed using statistical analysis, content analysis, and business process analysis. Results: the interrelationship between startups and large companies in acceleration programs enhances the development of capabilities for startups because it facilitates access and assimilation of knowledge. On the other hand, knowledge transformation and exploitation help the modification of the structure, processes, and resources of startups to serve the large company, and the development of new products and services to the market occurs modestly and incrementally. Conclusions: the study highlights how the formal actions of corporate accelerator programs by large firms contribute to the development of absorptive capacity in startups.

Keywords: corporate accelerator; absorptive capacity; dynamic capabilities; business process management; interorganizational relationships.

Editor-chefe: Wesley Mendes-Da-Silva (Fundação Getulio Vargas, EAESP, Brasil) Pareceristas: Edgard Cornacchione (Universidade de São Paulo, FEA, Brasil) Marcelo Tsuguio Okano (Centro E. E. T. Paula Souza [CEETEPS], Brasil) Recebido em: 16/12/2018
Última versão recebida em: 05/05/2020 Aceite em: 17/05/2020 


\section{INTRODUÇÃO}

As capacidades dinâmicas têm se mostrado benéficas para organizações em ambientes turbulentos e mutáveis (Schilke, Hu, \& Helfat, 2018). Por isso, o fenômeno tem despertado interesse de pesquisadores em estratégia, mudanças organizacionais e vantagem competitiva. Embora os estudos em capacidades dinâmicas apresentem crescimento exponencial (Schilke et al., 2018), trabalhos empíricos foram predominantemente conduzidos com empresas estabelecidas e pouco se sabe sobre como exatamente ocorrem em startups (Autio, George, \& Alexy, 2011; Ma, Zhou, \& Fan, 2015).

Um dos fatores relacionados às capacidades dinâmicas é a capacidade de absorção, cujo conceito seminal de Cohen e Levinthal (1990) foi expandido com a incorporação de uma perspectiva dinâmica por Zahra e George (2002), definindo-a como um conjunto de rotinas organizacionais e processos pelos quais as empresas adquirem, assimilam, transformam e utilizam os conhecimentos externos para produzir uma capacidade organizacional dinâmica. Embora tão destacados quanto recursos, com poucas exceções, as rotinas organizacionais específicas e os processos que constituem a capacidade de absorção das empresas são pouco explorados pelos pesquisadores, constituindo uma área de estudo promissora (Lewin, Massini, \& Peeters, 2011).

Assim, capacidade de absorção é vista como uma competência essencial para as organizações e a forma como é efetivamente implementada nas empresas permanece relativamente mal conhecida (Aribi \& Dupouët, 2016). Esses autores argumentam que as poucas obras existentes apresentam a capacidade de absorção como um processo essencialmente linear e a forma como as diferentes fases desse processo são realmente realizadas continua a ser pouco estudada, menos ainda em empresas nascentes ou no início das atividades de um negócio, as chamadas startups (Hindle, 2002).

Segundo Blank e Dorf (2014), startups são organizações temporárias que buscam um modelo de negócios escalável, recorrente e lucrativo. Sobre esse aspecto, as grandes empresas auxiliam as startups a construírem seus modelos de negócios na medida em que propiciam acesso a mercados já estabelecidos, branding, vantagens de reputação, acesso a propriedade intelectual e know-how técnico, além de ajudar as startups a superarem algumas barreiras de entrada e inexperiência (Ceccagnoli, Forman, Huang, \& Wu, 2012; Eisenmann, Parker, \& Alstyne, 2009) para ganharem aceitabilidade no mercado (Groote \& Backmann, 2020).
Ou seja, relacionamentos interorganizacionais entre startups e grandes empresas podem ser positivos para ambas, no entanto, as diferenças tanto estratégicas quanto organizacionais entre essas empresas trazem um desafio adicional tanto para sua aproximação quanto para a gestão dessas parcerias. Uma forma de construir pontes entre essas organizações é o uso dos programas estruturados de aceleração liderados por corporações mundiais, que, embora relativamente recentes, vêm aumentando no Brasil e no mundo (Moschner, Fink, Kurpjuweit, Wagner, \& Herstatt, 2019; Shankar \& Shepherd, 2019; Urbaniec \& Żur, 2020). Dentre os diversos mecanismos que explicam o papel das aceleradoras corporativas, destaca-se a prestação de suporte para aumentar o acesso e o crescimento das startups no mercado (Crișan, Salanță, Beleiu, Bordean, \& Bunduchi, 2019).

Adicionalmente, grande parte das pesquisas sobre relacionamentos interorganizacionais entre empresas de portes ou maturidades distintas foi realizada sob a perspectiva das grandes empresas, revelando uma escassez de estudos focados em startups (Chaudhary \& Batra, 2018; Dooley, Kenny, \& Cronin, 2015; Evangelista \& Mac, 2016; Huang, Rice, \& Martin, 2015). No entanto, há evidências empíricas de que a relação com organizações mais maduras pode beneficiar também as empresas nascentes. Stuart (2000) descobriu que grandes empresas com tecnologias líderes eram consideradas parceiras altamente valiosas, particularmente para empresas mais jovens e menores, muitas vezes sem os recursos que lhes poderiam permitir acesso a tal tecnologia. Além disso, startups se beneficiam muito de alianças eficazes, em parte devido às oportunidades aprimoradas de desenvolver capacidades (Baum, Calabrese, \& Silverman, 2000). Para Wasiuzzaman (2019), as alianças com grandes empresas não só ajudam as startups em sua gestão e aspectos tecnológicos, mas também melhoram suas condições financeiras e vantagem competitiva.

Considerando, portanto, que relacionamentos interorganizacionais com grandes empresas beneficiam as startups, é oportuno entender como a capacidade de absorção ocorre nessas empresas, com o objetivo de criação e sustentabilidade de vantagem competitiva. Para tal, e considerando a dinamicidade da capacidade de absorção, é necessário entender os processos organizacionais da firma, ou seja, suas rotinas e padrões de práticas e aprendizados, que estão na essência do conceito de capacidades dinâmicas (Teece, Pisano, \& Shuen, 1997).

Surge, neste estudo, a oportunidade de sistematizar o conhecimento empírico e teórico, apresentandoresultados que descrevem os processos de negócio relacionados à operacionalização do 
conceito de capacidade de absorção nas startups, explorando um problema ainda pouco estudado. Isso foi feito por meio da abordagem gerencial de gerenciamento de processos de negócio ou business process management (BPM). O BPM vai além das rotinas organizacionais e estruturas funcionais, representando uma nova forma de visualizar as operações de negócio (Burlton, 2010).

Dentro dessa problemática de investigação dos processos que compõem efetivamente a capacidade de absorção em startups, surge a pergunta motivadora deste estudo: nos relacionamentos interorganizacionais entre grandes empresas e startups, como as startups desenvolvem capacidade de absorção, sob a perspectiva do gerenciamento de processos de negócio, com o objetivo de criar vantagem competitiva?

A partir do problema de pesquisa, o objetivo geral deste estudo é analisar os processos de negócio que constituem a capacidade de absorção das startups, bem como sua implementação e realização, a fim de promover vantagens competitivas. Para tanto, foi analisada a relação interorganizacional das startups com grandes empresas por meio de programas formais de aceleração corporativa.

\section{REFERENCIAL TEÓRICO}

\section{Relacionamentos interorganizacionais}

Relações entre organizações são vistas como importantes fontes de recursos e aprendizado e, desde que efetivamente gerenciadas, com potencial para levar à vantagem competitiva (Ireland, Hitt, \& Vaidyanath, 2002). Há pelo menos seis diferentes paradigmas teóricos amplamente utilizados para embasar a formação de relacionamentos interorganizacionais, incluindo economia de custos de transação, dependência de recursos, escolha estratégica, teoria de partes interessadas, aprendizado organizacional e teoria institucional (Barringer \& Harrison, 2000). O aprendizado organizacional modela o recorte teórico deste estudo, pois considera-se, aqui, que as empresas formam parcerias para capitalizar as oportunidades de aprendizagem organizacional.

Nas redes de colaboração, alguns casos estão se destacando, como as alianças entre grandes empresas e startups, que são parceiros altamente diferentes, como apontado por Groote e Backmann (2020). Essas diferenças começam na própria seleção de outras organizações com as quais inovar: enquanto as startups se baseiam nas suas próprias redes de contato para encontrar um parceiro, as empresas consolidadas possuem mecanismos profissionais de monitoramento de eventuais alianças, sendo inclusive as startups, mas em especial aquelas que oferecem soluções mais inovadoras (Groote \& Backmann, 2020). Quando se trata de agilidade, startups têm uma vantagem adicional sobre as grandes corporações, ao passo que as grandes corporações possuem controle sobre recursos que as startups estão longe de alcançar. Percebe-se uma tendência, na qual as grandes corporações começaram a enxergar oportunidades de inovação empresarial nas startups, substituindo capital próprio por tecnologia compartilhada, para conectar dois mundos com menos custos organizacionais e maior velocidade e agilidade (Weiblen \& Chesbrough, 2015). Ainda, há traços opostos de inovação entre grandes empresas e startups (Jang, Lee, \& Yoon, 2017), sugerindo que estas últimas precisam de colaboração para entrada no mercado com suas tecnologias disruptivas e que as grandes empresas possuem sucesso tecnológico com base em sua grande escala de mercado e canais de distribuição, mas precisam utilizar a agilidade e o conhecimento especializado da startup para estimular suas próprias atividades de inovação (Hogenhuis, van den Hende, \& Hultink, 2016). Esses traços opostos, não obstante, implicam possibilidades vantajosas de inovação aberta complementar entre grandes empresas e startups (Jang et al., 2017), mas geram desafios para a gestão dessas parcerias.

Assim, as organizações são impulsionadas a encontrar formas e estruturas adequadas para minimizar essas características tão díspares entre grandes corporações e startups, aproximando-as para desenvolver capacidades que resultem em inovação. As aceleradoras corporativas são um modelo efetivo para isso, pois são caracterizadas por mecanismos que apoiam a validação de ideias e produtos, que fornecem modelos de aprendizagem e que dão suporte ao crescimento e entrada no mercado a empresas que estão iniciando suas atividades, da mesma forma que prestam apoio à inovação (Crișan et al., 2019).

\section{Capacidade de absorção em startups}

Capacidade de absorção é uma capacidade dinâmica da firma e seus efeitos refletem a aprendizagem organizacional, a partilha de conhecimentos, a inovação e o desempenho da empresa (Flatten, Engelen, Zahra, \& Brettel, 2011). Zahra e George (2002), colocando-a numa perspectiva de capacidade dinâmica, destacam dois subconjuntos de capacidade de absorção: potencial e realizada. Capacidade potencial compreende aquisição e assimilação de conhecimento e capacidade realizada a transformação e o aproveitamento do conhecimento. $\mathrm{O}$ modelo proposto por Zahra e George (2002), que conecta os dois subconjuntos de capacidade de absorção, assim 
como as fontes externas de conhecimento, indica que tanto a capacidade de absorção potencial quanto a realizada contribuem diferencialmente, porém, de forma complementar para o desenvolvimento de vantagem competitiva nas organizações.

Embora existam muitas maneiras pelas quais uma empresa pode obter vantagem competitiva, Zahra e George (2002) esclarecem que a inovação e a flexibilidade estratégica são os fatores mais importantes em mercados dinâmicos e pertencem ao subconjunto de capacidade de absorção potencial. As capacidades de transformação e exploração, que a capacidade de absorção realizada compreende, são susceptíveis de influenciar o desempenho organizacional, por meio da inovação de produtos e processos.

Nesse contexto, a inovação pode aumentar a probabilidade de sobrevivência e sustentabilidade da vantagem competitiva de uma startup na medida em que permite a criação de capacidades dinâmicas e melhora sua capacidade de absorção (Hyytinen, Pajarinen, \& Rouvinen, 2015). Não obstante, Rodríguez-Serrano e Martín-Armario (2019) consideram capacidade de absorção uma capacidade dinâmica distinta para apoiar o desempenho inovador de startups internacionalizadas quando estas desenvolvem a habilidade de obter conhecimento externo e assimilar seu valor, além da capacidade de usar o conhecimento e explorálo, em ambientes de negócio globais, competitivos e dinâmicos. Já em economias com baixos níveis de empreendedorismo e crescimento econômico estagnado, como a do Japão, as startups enfrentam dificuldades para acessar fontes de conhecimento externo devido à falta de capacidade de absorção (Kato, 2020).

Percebe-se, nessa discussão, a relevância da capacidade de absorção para o desenvolvimento sustentável de conhecimento e inovação em organizações. Em se tratando de startups, por encontrarem-se no início de suas atividades e serem pequenas, isso pode ser mais crítico já que há falta não somente de acúmulo de recursos técnicos e habilidades gerenciais (Hoang \& Antoncic, 2003), mas também de credibilidade no mercado (Stuart, 2000). Assim, o aprendizado por meio da capacidade de absorção em relacionamentos com outras organizações é relevante para minimizar essas fragilidades (Tidd, Bessant, \& Pavitt, 2008).

A relevância das capacidades para as startups é reconhecida no estudo de Savarese, Orsi e Belussi (2016), em que os autores mostram que o desenvolvimento de capacidades dinâmicas, considerado por eles como o investimento em recursos humanos e novas rotinas, é significativo para o crescimento desse tipo de empresa. No entanto, esse tema é pouco estudado. Um dos poucos trabalhos nessa temática (Ma et al., 2015) mostra que as capacidades dinâmicas da startup são diferentes das de empresas bem estabelecidas, uma vez que elas são desenvolvidas muito em razão da experiência do empreendedor e da mobilização de recursos complementares externos. Portanto, é necessário entender melhor como a parceria interorganizacional possibilita o desenvolvimento de capacidades, que, por sua vez, levariam ao sucesso das startups.

\section{Gerenciamento de processos de negócio}

De acordo com Teece, Pisano e Shuen (1997), o conceito de capacidades dinâmicas tem como essência os processos organizacionais da firma (jeito da empresa de fazer as coisas, ou seja, as rotinas e padrões de práticas e aprendizados da organização), que são, por sua vez, formados pelas posições (recursos e ativos disponíveis) e moldados pela própria evolução da história da firma (caminhos já percorridos pela empresa, considerando as ameaças e oportunidades produtivas identificadas). Analogamente, Zahra e George (2002) adotam uma perspectiva de processo sobre a capacidade de absorção, enfatizando o aproveitamento do conhecimento externo e a combinação com o conhecimento interno da firma, para influenciar os resultados organizacionais. Os autores afirmam que a capacidade de absorção é vista como uma capacidade dinâmica embutida em rotinas e processos de uma empresa, tornando possível analisar os estoques e fluxos de conhecimento, relacionando essas variáveis para a criação e sustentabilidade de vantagem competitiva. Como se pode observar, existe uma relação latente entre o constructo capacidade de absorção e a abordagem gerencial de gerenciamento de processos de negócio.

O gerenciamento de processos de negócio, mais conhecido pelo termo em inglês business process management (BPM), é uma abordagem gerencial e um conjunto de tecnologias que provê suporte ao gerenciamento por processos, que por sua vez está envolvido com o gerenciamento do desempenho corporativo. Os processos de negócios descrevem como as empresas se organizam para realizar um determinado trabalho. Em uma concepção mais genérica, processos de negócio são qualquer conjunto de atividades realizadas por uma organização, sendo iniciados por um evento, transformando informações, materiais ou compromissos comerciais e produzindo uma saída de valor para a organização ou partes interessadas do processo. Esse trabalho organizado entrega valor para os clientes ou apoia/gerencia outros processos, podendo ser ponta a ponta, interfuncional e até mesmo interorganizacional (Association of Business Process Management Professionals [ABPMP], 2013). 
Com o propósito de analisar os processos de negócio que constituem a capacidade de absorção das startups, buscando descrever como eles são realizados e implementados, este estudo utilizou uma abordagem especializada para a iniciativa de modelar os processos encontrados na pesquisa, proporcionando uma análise de perspectiva organizacional (ABPMP, 2013). Tal abordagem envolveu o estilo de documentação SIPOC, que é a sigla para Supplier, Input, Process, Output e Customer, aplicada por meio do preenchimento de uma tabela com os elementos que compõem a sigla. A Figura 1 mostra a representação da matriz SIPOC (ASQ Service Quality Division, 2016) utilizada no estudo.

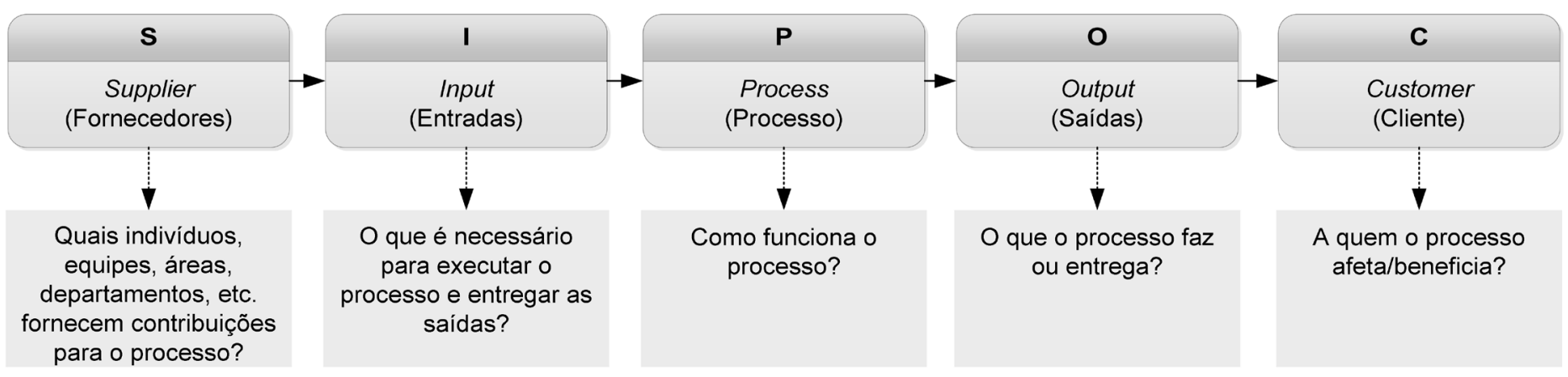

Figura 1. Matriz SIPOC.

Fonte: Adaptado de ASQ Service Quality Division (2016, May 6). SIPOC (suppliers, inputs, process, outputs, customers) diagram. Retrieved from http://asqservicequality.org/glossary/sipoc-suppliers-inputs-process-outputs-customers-diagram/

Segundo a ABPMP (2013), o modelo SIPOC pode ser aplicado em situações em que seja necessário obter um consenso sobre quais aspectos de um processo devem ser estudados. O uso dessa técnica permitiu que os processos de negócio que constituem a capacidade de absorção das startups fossem identificados e arranjados de forma simplificada em uma tabela, facilitando a visualização das entradas e saídas dos processos.

\section{Relação entre gerenciamento de processos de negócio e capacidade de absorção}

O gerenciamento de processos de negócio e seu papel no aumento da capacidade de absorção receberam atenção especial no trabalho de Manfreda, Kovacic, Štemberger e Trkman (2014), no qual o gerenciamento de processos e seus benefícios manifestaram-se especificamente em termos de capacidade dos funcionários para entender o trabalho de outros, propor novas mudanças ou aceitar as propostas de outros, todos eles aumentando o nível de capacidade de absorção. Uma capacidade de absorção elevada denota que as organizações podem aprender a usar novos conhecimentos em seus processos e implementar mudanças que melhorem suas operações.

Para Srivardhana e Pawlowski (2007), o nível de capacidade de absorção de uma empresa não é simplesmente uma soma das 'capacidades de absorção' de funcionários individuais, e uma empresa não pode depender apenas de seus funcionários para desenvolver a capacidade de absorção. A fim de melhorar e sustentar a capacidade de absorção, as empresas devem ir além das estratégias de desenvolvimento humano para desenvolver rotinas e processos organizacionais para adquirir, assimilar, transformar e explorar o conhecimento e, nesse contexto, entra um vasto conjunto de técnicas de análise de processos como o Lean Management, Six Sigma, Workflow Management e Process Modeling, para citar alguns exemplos.

Gutiérrez, Bustinza e Molina (2012) consideram o gerenciamento de processos uma importante prática de Six Sigma e observam seus efeitos positivos sobre o desempenho organizacional, por meio da capacidade de absorção. Como consequência, visualizar o Six Sigma através da lente do gerenciamento do conhecimento e da aprendizagem organizacional pode levar a insights sobre como criar, reter e difundir o conhecimento usando um método estruturado. $\mathrm{O}$ gerenciamento de processos Six Sigma procura detectar e corrigir erros, estimulando a absorção de conhecimento sobre processos, na medida em que a criação de conhecimento ocorre por meio da aprendizagem gerada pelos processos formais de melhoria. $\mathrm{O}$ conhecimento também pode ser criado mediante a resolução de problemas de forma programável, como, por exemplo, uma sequência de etapas e um conjunto de ferramentas. Assim, o uso de procedimentos e técnicas estruturadas, bem como ferramentas associadas ao gerenciamento de processos Six Sigma, facilita a aquisição de conhecimento, pois 
a existência de uma linguagem comum, metas ou ferramentas compartilhadas etc., favorecem a absorção do conhecimento.

Corroborando o pensamento de Manfreda et al. (2014), Gutiérrez et al. (2012) argumentam que vários estudos observaram que o uso de mecanismos para integrar os trabalhadores tem um efeito positivo na capacidade de absorção, levando em consideração o gerenciamento de processos incluídos na metodologia Six Sigma. As equipes que utilizam mecanismos de comunicação lateral, que facilitam o fluxo de conhecimento por meio de fronteiras funcionais, permitem que os funcionários combinem o conhecimento existente ao adquirido recentemente, auxiliando a integrar os diferentes corpos de conhecimento e a criar rotinas dentro das unidades.

Srivardhana e Pawlowski (2007) destacam que a capacidade de absorção não depende apenas da disponibilidade de novos conhecimentos ou informações; os membros da organização também precisam da capacidade de transmitir sua aprendizagem entre si e desenvolver estruturas cognitivas comuns sobre a aplicação do conhecimento compartilhado. Em última análise, o desenvolvimento da capacidade de absorção pode proporcionar às organizações condições favoráveis para a construção de novas capacidades para criar e implantar conhecimento, melhorando os processos de negócios.

Pode-se afirmar, então, que existe uma relação entre gerenciamento de processos de negócio e capacidade de absorção, em que o gerenciamento de processos pode auxiliar a operacionalizar e potencializar os processos de aprendizagem organizacional, por meio da capacidade de absorção, da mesma forma que o desenvolvimento da capacidade de absorção pode proporcionar às organizações condições favoráveis para melhoria contínua dos processos críticos. Sendo a capacidade de absorção um conjunto de rotinas que envolvem a capacidade das empresas em iniciar mudanças a partir de dentro, bem como identificar e assimilar as ideias do ambiente externo, a gestão de processos de negócio conduz à aplicação sistemática destas rotinas organizacionais específicas e processos que constituem a capacidade de absorção das empresas, para geração de valor e vantagem competitiva.

\section{MÉTODO}

Procedimentos metodológicos e definição das unidades de análise

Esta pesquisa foi baseada em um desenho qualitativo de estudo de casos múltiplos (Yin, 2015) para examinar as parcerias entre grandes empresas e startups, destacando a análise dos processos de negócio que constituem a capacidade de absorção de startups inseridas em programas de aceleração corporativa. Medidas específicas foram desenvolvidas no protocolo de estudo de caso para conduzir os procedimentos de coleta e análise dos dados. Segundo Yin (2015), o protocolo é uma maneira importante de aumentar a confiabilidade de pesquisa de estudo de caso. A Figura 2 integrou o protocolo de pesquisa e sintetiza os procedimentos adotados para a coleta dos dados.

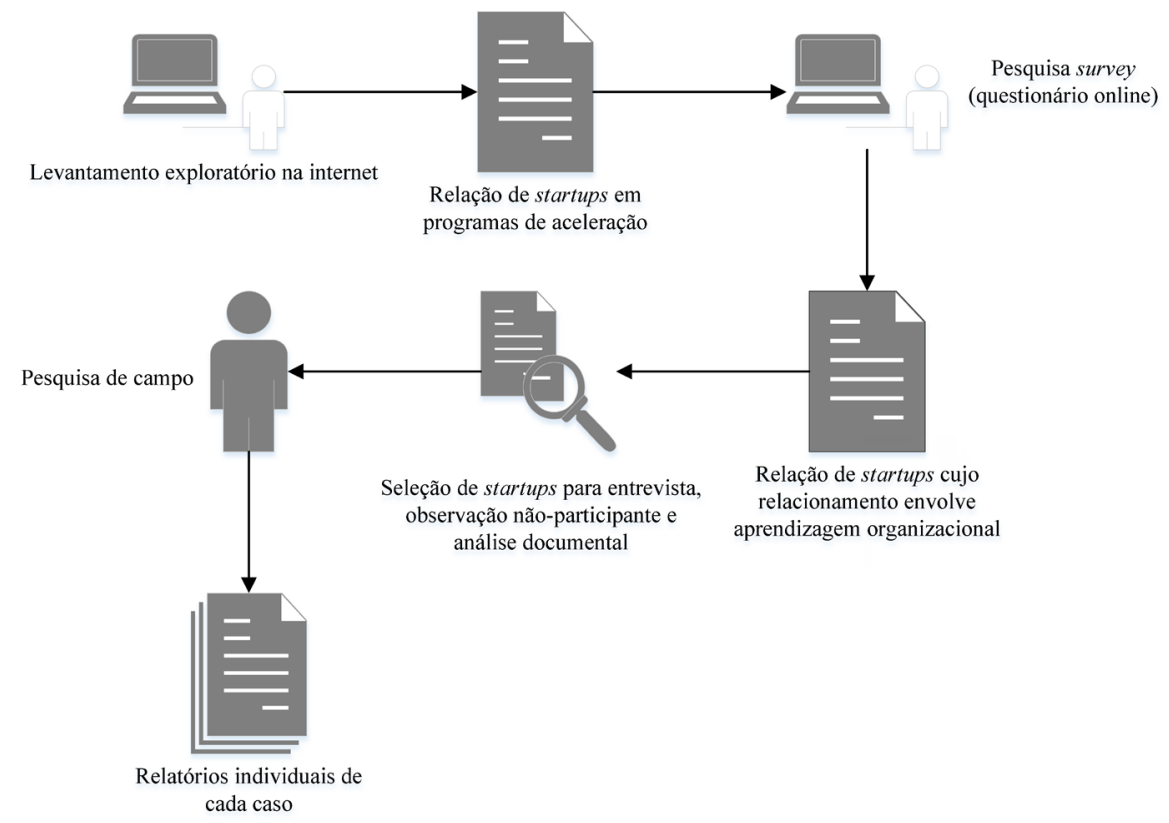

Figura 2. Procedimentos de coleta de dados. 
A primeira etapa da pesquisa envolveu um levantamento exploratório via internet por grandes empresas que investem em programas corporativos de aceleração de startups, como AES Brasil (AES Brasil Inovação), Bradesco (Inovabra Startups), Braskem (Braskem Labs), Enel (Energy Start), Google (Campus São Paulo), Itaú Unibanco (Cubo), Oi (Oito), Porto Seguro (Oxigênio Aceleradora), Samsung (Ocean), Senior Solution (Inove Senior) e Telefônica Brasil (Wayra) e, posteriormente, por startups inseridas nesses programas corporativos de aceleração. Essa última busca resultou em 175 startups, contudo, 160 estavam com os dados disponíveis para a coleta de informações. As startups estavam distribuídas em cinco programas de aceleração fomentados por grandes empresas (Braskem Labs, Campus São Paulo, Cubo, Oxigênio Aceleradora e Wayra).

Na sequência, foi realizada a segunda etapa do estudo, que foi uma pesquisa de levantamento (survey) utilizando um questionário on-line junto às 160 startups, com o objetivo de evidenciar startups que indicassem um grau razoável de capacidade de absorção, destacando a aprendizagem organizacional junto à grande empresa. Para que esse objetivo fosse atingido, foram utilizadas como referência as escalas que se propõem a identificar capacidade de absorção de Pavlou e El Sawy (2006), Camisón e Forés (2010), Flatten, Engelen, Zahra e Brettel (2011) e JiménezBarrionuevo, García-Morales e Molina (2011).

A utilização da pesquisa survey foi decisiva para a definição da primeira amostra do estudo, buscando startups que indicassem um grau razoável de capacidade de absorção e informações relevantes para caracterizar o relacionamento interorganizacional com a grande empresa. Nessa etapa, obteve-se resposta de 34 startups convidadas a participar da pesquisa, gerando uma amostra de 33 startups consideradas válidas para o estudo. Dessa amostra, 11 startups foram selecionadas para serem investigadas em profundidade, por apresentarem uma tendência positiva de absorver conhecimento junto à grande empresa e reconhecerem a relevância da parceria. Todas foram contatadas e sete delas aceitaram participar do estudo: BR Goods e Raiz, vinculadas ao programa Braskem Labs da Braskem e Bynd, Confere Cartões, Evnts, Nexoos e Psicologia Viva, inseridas no programa da Oxigênio Aceleradora fomentado pela Porto Seguro.

Na pesquisa de campo, terceira etapa, foram realizadas entrevistas semiestruturadas com o proprietário, gestor ou responsável pela startup, obtendo-se informações detalhadas e que foram utilizadas na análise qualitativa. As entrevistas ocorreram entre dezembro de 2017 e janeiro de 2018, sendo gravadas e transcritas para evitar erros de interpretação, permitindo uma análise mais aprofundada. O roteiro de entrevista foi baseado na escala de Pavlou e El Sawy (2006).
Além das entrevistas, foram utilizadas como fontes de evidências a observação direta não participante e análise de documentos internos das startups, como sínteses de reuniões, dashboards de gerenciamento de projetos e tarefas e materiais coletados na internet, construindo um corpus de pesquisa (Bauer \& Gaskell, 2015) pautado nos princípios da triangulação de dados (Sampieri, Collado, \& Lucio, 2013; Yin, 2015).

Técnicas de análise estatística (Field, 2009) foram utilizadas para a pesquisa survey, além da análise de processos de negócio (ABPMP, 2013) e análise de conteúdo (Bardin, 2016) para a etapa de exploração do corpus - que contou com operações auxiliadas por computador -, constituída essencialmente pela codificação e categorização das informações coletadas.

No que se refere ao uso da informática como ferramenta de auxílio à análise dos dados, evidenciase neste estudo o uso dos softwares Iramuteq (interface de $R$ pour les analyses multidimensionnelles de textes et de questionnaires) e NVivo 11 para a análise qualitativa dos dados textuais, auxiliando na codificação dos significados do material reunido. De forma complementar, o software SPSS Statistics 17 foi utilizado para tratamento dos dados da pesquisa survey e o Bizagi Modeler para a iniciativa de modelagem de processos de negócio.

\section{ANÁLISE DOS RESULTADOS}

\section{Codificação e categorização dos dados coletados}

Evidencia-se no dendograma da Figura 3 que, dos dados obtidos com as sete startups pesquisadas, há quatro conceitos centrais envolvidos no discurso dos entrevistados ao responderem às perguntas da entrevista, de acordo com análise do software Iramuteq.

É possível verificar que a classe 3 representa $21,1 \%$ dos segmentos de texto do corpus e apresenta as principais palavras relacionadas às grandes empresas que se relacionam com as startups pesquisadas, neste caso, Braskem e Porto Seguro. Nessa classe também se nota algumas características das grandes empresas que corroboram as informações coletadas nas entrevistas e análise de documentos internos, como a exigência de reuniões periódicas junto às startups participantes dos programas de aceleração e a disponibilização de um executivo ou 'padrinho' para acompanhar o processo, que atuava como um mentor. As startups relataram que tinham acesso facilitado aos executivos de diversas áreas e especialidades dentro da grande empresa, podendo solicitar mentorias e treinamentos específicos de acordo com suas necessidades. 


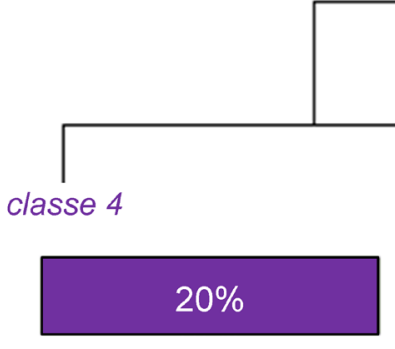

usar
objetivo
área
riçar
definir
tarefa
departamento
gestão
específico
colocar
ferramenta
resultado
separar
okr
acompanhar
funcionalidade
board
flexível
documentar
mail
fluxo
metodologia
venda
implementar
prioriza
impacto
mandar
comunicação

Figura 3. Dendograma do corpus textual com palavras-chave.

A classe 1 representa 24,5\% dos segmentos de texto e, na sua análise, fica claro que o conceito central é o programa de aceleração promovido pelas grandes empresas, e a proximidade de contexto com a classe 3 é evidente. Algumas palavras presentes nessa classe indicam que os programas de aceleração são temporais, ou seja, têm um início, meio e fim. Contudo, observouse nas entrevistas que mesmo após o término formal do programa de aceleração, as startups continuaram mantendo contato com as grandes empresas e tendo acesso aos mentores. Percebe-se também na classe 1 a presença de verbos que indicam as novas possibilidades que surgiram para as startups inseridas nos programas, desde a mudança expressiva na gestão e desempenho organizacional até a abertura de mercado para novos clientes, fatos também observados nos dashboards de gerenciamento de projetos e tarefas das startups.

Já as classes 2 e 4 representam 34,5\% e $20 \%$ do conteúdo do corpus, respectivamente, nas quais se concentra um conjunto de palavras que expressam o discurso dos entrevistados relacionado à capacidade de absorção e processos de negócio. A análise das palavras da classe 2 permitiu identificar que a capacidade de aquisição e assimilação do conhecimento, ou seja, a capacidade de absorção potencial, é muito mais desenvolvida nas startups do que a capacidade de absorção realizada, pois as palavras concentram-se nessas duas dimensões. De fato, o foco dos programas de aceleração corporativa é disponibilizar os conhecimentos da grande empresa para compartilhar experiências com os empreendedores em fase inicial, ajudando a startup a definir estratégias e utilizar ferramentas para melhorar a gestão e o desempenho organizacional.

O uso do software NVivo como auxílio às operações de recorte e codificação do material textual proveniente das entrevistas deu suporte estatístico às análises realizadas, apresentando o agrupamento de palavras por similaridade de codificação representado por um dendograma, como mostra a Figura 4. 


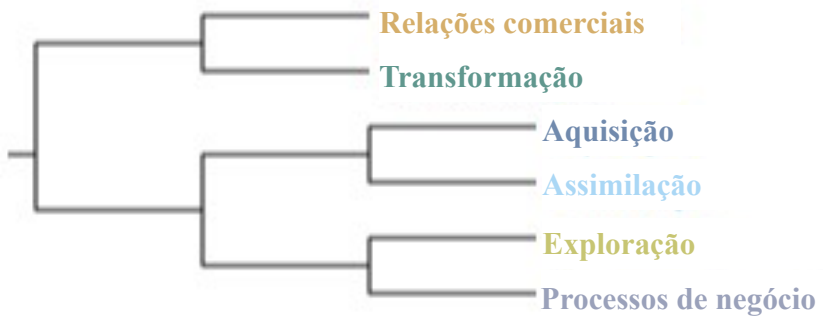

Figura 4. Nós em cluster por similaridade de codificação.

Nota-se o agrupamento dos 'nós' Aquisição e Assimilação, evidenciando uma proximidade que corrobora a base teórica em estudo, pois são as duas dimensões da capacidade de absorção potencial. A análise mostra que as startups investigadas apresentam um desempenho coerente quanto à capacidade de adquirir e assimilar conhecimento, pois o próprio movimento de entrar em um programa de aceleração corporativa demonstra a habilidade da startup em identificar e obter conhecimentos a partir de fontes externas. Da mesma forma, evidenciouse nas entrevistas e observação direta a habilidade das startups em analisar, interpretar e compreender os conhecimentos adquiridos externamente, criando rotinas que promovem a disseminação do conhecimento adquirido da grande empresa, por meio de reuniões, ferramentas de informática e processos administrativos.

No mesmo nível da primeira aglomeração surge o agrupamento Exploração e Processos de negócio. Porém, antes da interpretação dessa descoberta, faz-se necessário observar o último e mais distante agrupamento: Relações comerciais e Transformação. Sabe-se que além da busca por conhecimento, as startups veem nos programas de aceleração corporativa uma oportunidade para iniciar e manter relações comerciais com as grandes empresas. Nesse contexto, a capacidade das startups em combinar os conhecimentos existentes com os conhecimentos adquiridos da grande empresa sustenta a parceria comercial entre as duas organizações. O agrupamento Relações comerciais e Transformação, que se apresenta mais afastado dos demais, porém ligado a toda a aglomeração, distingue-se dos outros por apresentar uma forte representatividade para as startups. Retornando ao agrupamento Exploração e Processos de negócio, o conhecimento transformado é utilizado pelas startups para melhorar seu desempenho organizacional. É nesse estágio que os processos de negócio são estruturados nas startups, em que se criam rotinas, procedimentos e controle para as atividades críticas. De fato, a pesquisa evidenciou que as capacidades de transformação e exploração, decorrentes da capacidade de absorção realizada, são susceptíveis de influenciar o desempenho das startups por meio da inovação de processos e organizacional.
As descobertas apresentadas nesses agrupamentos indicam que as startups, dentro do programa de aceleração corporativa, desenvolvem a capacidade de absorção potencial de forma mais efetiva frente à capacidade de absorção realizada. Isso foi observado porque as startups concentram mais esforços nos processos referentes à aquisição e assimilação de conhecimento, já que elas veem como relevante para vantagem competitiva fortalecer as relações comerciais com a grande empresa. De fato, os produtos e serviços desenvolvidos pelas startups estudadas atendem em um primeiro momento à grande empresa com a qual se relacionam e, posteriormente, são expandidos para o mercado. Também é observado que a startup procura desenvolver processos internos para melhoria de desempenho seguindo orientações e diretrizes da empresa parceira. Isso mostra que os esforços das startups estão majoritariamente em adquirir e assimilar conhecimento da empresa parceira (capacidade potencial), mas também se observa iniciativas relevantes de transformação interna para exploração de mercado (capacidade realizada), mesmo que ainda muito ligadas aos interesses da empresa parceira.

Desenvolvimento de capacidade de absorção potencial e realizada em startups

O mapeamento dos macroprocessos que compõem a capacidade de absorção, sob a perspectiva do gerenciamento de processos de negócio, permitiu identificar os componentes que surgem nos programas de aceleração, apresentados nas Figuras 5 e 6, dando entendimento à capacidade de absorver conhecimento por meio do comportamento dos processos.

Segundo Zahra e George (2002), os esforços gastos em rotinas de aquisição de conhecimento possuem três atributos que podem influenciar o desenvolvimento da capacidade de absorção: intensidade, velocidade e direção. A intensidade dos esforços das startups para identificar e reunir conhecimento dentro dos programas de aceleração corporativa é potencializada pela oferta de capacitações especializadas e rede de mentores disponibilizada pelas grandes empresas. Os autores supracitados afirmam que quanto maior o esforço, mais rapidamente a empresa construirá as capacidades necessárias e, de fato, essa afirmação pode ser confirmada nesta pesquisa, pois ambos os programas de aceleração têm duração de apenas quatro meses e dentro desse período, determinaram a qualidade da capacidade de aquisição das startups. A direção de acumular conhecimento, ou seja, as capacitações e mentorias, também atenderam à necessidade de se ter diferentes áreas de especialização dentro da startup, para importar tecnologias com sucesso (Zahra \& George, 2002). 


\begin{tabular}{|c|c|c|c|c|c|}
\hline & $\begin{array}{c}\text { Supplier (Fornecedor) } \\
\text { Ações promovidas pela } \\
\text { aceleradora corporativa }\end{array}$ & $\begin{array}{l}\text { Input (Entradas) } \\
\text { Processos iniciados } \\
\text { pela startup }\end{array}$ & $\begin{array}{c}\text { Process (Processos) } \\
\text { Macroprocessos realizados } \\
\text { pela startup }\end{array}$ & $\begin{array}{c}\text { Output (Saídas) } \\
\text { Capacidades desenvolvidas } \\
\text { pela startup }\end{array}$ & $\begin{array}{c}\text { Customer (Cliente) } \\
\text { Vantagem competitiva } \\
\text { para a startup }\end{array}$ \\
\hline \multirow{2}{*}{ 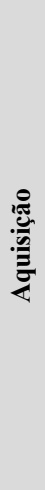 } & Capacitações & $\begin{array}{l}\text { Acompanhamento da } \\
\text { programação previamente } \\
\text { agendada pela aceleradora; } \\
\text { Solicitação, por parte dos } \\
\text { gestores da startup, de } \\
\text { capacitações específicas e de } \\
\text { acordo com as necessidades. }\end{array}$ & $\begin{array}{l}\text { Participar dos workshops e } \\
\text { palestras programadas pela } \\
\text { aceleradora; } \\
\text { Participar das capacitações } \\
\text { personalizadas e especíicas. }\end{array}$ & $\begin{array}{l}\text { Aquisição de conhecimentos } \\
\text { por parte dos gestores e } \\
\text { equipes; } \\
\text { Descobrimento de } \\
\text { ferramentas úteis à gestão } \\
\text { empresarial; } \\
\text { Busca por aprimoramento do } \\
\text { planejamento estratégico. }\end{array}$ & $\begin{array}{l}\text { Flexibilidade estratégica; } \\
\text { Inovação organizacional. }\end{array}$ \\
\hline & Rede de mentores & $\begin{array}{l}\text { Alinhar-se ao programa de } \\
\text { mentoria empreendedora } \\
\text { estabelecido pela aceleradora; } \\
\text { Solicitação, por parte dos } \\
\text { gestores da startup, de apoio } \\
\text { do mentor. }\end{array}$ & $\begin{array}{l}\text { Acessar a rede de mentores } \\
\text { disponibilizada; } \\
\text { Participar das sessões de } \\
\text { mentoria. }\end{array}$ & $\begin{array}{l}\text { Aquisição de novas } \\
\text { perspectivas e expertise; } \\
\text { Conhecimento de } \\
\text { informações relevantes sobre } \\
\text { o mercado; } \\
\text { Formação e manutenção de } \\
\text { uma rede de contatos. }\end{array}$ & Flexibilidade estratégica. \\
\hline 宽 & $\begin{array}{l}\text { Reuniões periódicas e } \\
\text { comunicação efetiva }\end{array}$ & $\begin{array}{l}\text { Atender às reuniões } \\
\text { semanais programadas pela } \\
\text { aceleradora; } \\
\text { Reuniões agendadas, de } \\
\text { acordo com as necessidades e } \\
\text { solicitações da startup; } \\
\text { Utilização de software para a } \\
\text { gestão das informações. }\end{array}$ & $\begin{array}{l}\text { Participar das reuniões; } \\
\text { Registrar as reuniões em atas; } \\
\text { Realizar of follow-up das } \\
\text { reuniões; } \\
\text { Intercambiar as informações } \\
\text { entre as equipes. }\end{array}$ & $\begin{array}{l}\text { Criação de um repositório de } \\
\text { informações; } \\
\text { Comunicação efetiva entre } \\
\text { startup e grande empresa; } \\
\text { Interação entre } \\
\text { departamentos; } \\
\text { Análise e compartilhamento } \\
\text { de informações. }\end{array}$ & Inovação organizacional. \\
\hline
\end{tabular}

Figura 5. Processo de aquisição e assimilação de conhecimento.

\begin{tabular}{|c|c|c|c|c|c|}
\hline & $\begin{array}{c}\text { Supplier (Fornecedor) } \\
\text { Ações promovidas pela } \\
\text { aceleradora corporativa }\end{array}$ & $\begin{array}{l}\text { Input (Entradas) } \\
\text { Processos iniciados } \\
\text { pela startup }\end{array}$ & $\begin{array}{c}\text { Process (Processos) } \\
\text { Macroprocessos realizados } \\
\text { pela startup }\end{array}$ & $\begin{array}{c}\text { Output (Saídas) } \\
\text { Capacidades desenvolvidas } \\
\text { pela startup }\end{array}$ & $\begin{array}{c}\text { Customer (Cliente) } \\
\text { Vantagem competitiva } \\
\text { para a startup }\end{array}$ \\
\hline \multirow{2}{*}{ 莺 } & Relações comerciais & $\begin{array}{l}\text { Produto ou serviço já existente } \\
\text { (MVP) na startup; } \\
\text { Sinergia de negócio com a } \\
\text { grande empresa e/ou seus } \\
\text { clientes e parceiros. }\end{array}$ & $\begin{array}{l}\text { Adaptar-se às necessidades } \\
\text { da grande empresa e/ou seus } \\
\text { clientes e parceiros; } \\
\text { Desenvolver produtos e/ou } \\
\text { serviços em conjunto com a } \\
\text { grande empresa. }\end{array}$ & $\begin{array}{l}\text { Adaptação de produtos e/ou } \\
\text { serviços; } \\
\text { Melhorias na gestão } \\
\text { empresarial e no } \\
\text { desenvolvimento de produtos } \\
\text { e/ou serviços; } \\
\text { Estruturação de áreas } \\
\text { funcionais; } \\
\text { Aceitação de mudanças e novas } \\
\text { regras de negócio. }\end{array}$ & $\begin{array}{l}\text { Inovação organizacional; } \\
\text { Desempenho organizacional. }\end{array}$ \\
\hline & $\begin{array}{l}\text { Transformação organizacional } \\
\text { e mudança estratégica }\end{array}$ & $\begin{array}{l}\text { Mentalidade e ação } \\
\text { empreendedora. }\end{array}$ & $\begin{array}{l}\text { Alinhar estratégias, estruturas e } \\
\text { processos; } \\
\text { Apropriar-se de informações } \\
\text { para se adaptar ao ambiente; } \\
\text { Realizar mudanças } \\
\text { organizacionais. }\end{array}$ & $\begin{array}{l}\text { Novos insights; } \\
\text { Reconhecimento de } \\
\text { oportunidades; } \\
\text { Posicionamento competitivo. }\end{array}$ & $\begin{array}{l}\text { Inovação organizacional; } \\
\text { Desempenho organizacional. }\end{array}$ \\
\hline \multirow{2}{*}{ 总 } & $\begin{array}{l}\text { Estruturação de processos de } \\
\text { negócio }\end{array}$ & $\begin{array}{l}\text { Escalabilidade do modelo de } \\
\text { negócio; } \\
\text { Necessidade de atender aos } \\
\text { interesses da grande empresa; } \\
\text { Necessidade de compartilhar } \\
\text { informações entre as equipes. }\end{array}$ & $\begin{array}{l}\text { Criar rotinas e fluxos de } \\
\text { trabalho estruturados; } \\
\text { Utilizar metodologias e } \\
\text { ferramentas para melhorar o } \\
\text { desempenho das rotinas de } \\
\text { trabalho; } \\
\text { Criar uma estrutura funcional } \\
\text { para dar suporte aos processos. }\end{array}$ & $\begin{array}{l}\text { Colaboradores atuando como } \\
\text { força de trabalho organizada e } \\
\text { eficiente; } \\
\text { Produção de valor para os } \\
\text { clientes e stakeholders; } \\
\text { Adoção de procedimentos } \\
\text { estruturados e sistematizados; } \\
\text { Expansão das áreas funcionais. }\end{array}$ & $\begin{array}{l}\text { Inovação organizacional; } \\
\text { Desempenho organizacional. }\end{array}$ \\
\hline & $\begin{array}{l}\text { Desenvolvimento de novos } \\
\text { produtos ou serviços }\end{array}$ & $\begin{array}{l}\text { Plano de pesquisa e } \\
\text { desenvolvimento; } \\
\text { Contato com as equipes de } \\
\text { inovacão e técnica das grandes } \\
\text { empresas. }\end{array}$ & $\begin{array}{l}\text { Utilizar os canais e } \\
\text { infraestrutura da aceleradora. }\end{array}$ & $\begin{array}{l}\text { Modificações, customização ou } \\
\text { personalização dos produtos ou } \\
\text { serviços; } \\
\text { Desenvolvimento de novos } \\
\text { produtos específicos; } \\
\text { Transferência de } \\
\text { conhecimentos. }\end{array}$ & $\begin{array}{l}\text { Inovação incremental de } \\
\text { produtos. }\end{array}$ \\
\hline
\end{tabular}

Figura 6. Processo de transformação e exploração do conhecimento. 
O processo de aquisição de conhecimento gera novas ideias e descobertas que, muitas vezes, estão além da zona de busca de uma empresa e são negligenciadas, porque a empresa não pode facilmente compreendê-las. $\mathrm{O}$ conhecimento externo também é específico, o que muitas vezes impede que pessoas de fora compreendam ou reproduzam esse conhecimento (Zahra \& George, 2002). Com base nessas premissas, a realização de reuniões periódicas e sistematizadas, bem como a comunicação efetiva entre as startups e as grandes empresas, promove a assimilação do conhecimento, permitindo que as startups processem e internalizem o conhecimento gerado externamente.

Seguindo a base teórica proposta por Zahra e George (2002), a transformação muda o caráter do conhecimento por meio da biassociação ${ }^{1}$, que ocorre quando a empresa possui a capacidade de reconhecer dois conjuntos de informações aparentemente incongruentes e depois combinálos para chegar a um novo esquema. Essa capacidade, que surge do processo de biassociação, fica evidente nas startups que se relacionam com grandes empresas, principalmente pela diferença entre as formas empresariais e de realização do trabalho, que se tornam verdadeiros desafios para a obtenção de resultados quando ambos os lados trabalham juntos. É nas relações comerciais entre as grandes empresas e as startups que a origem de novas competências pode ser encontrada. Da mesma forma, os novos conhecimentos geram nas startups transformação organizacional e reformulação da estratégia competitiva, uma vez que os programas de aceleração oferecem a possibilidade de conexão e networking com os maiores e mais estratégicos players do mercado.

A ênfase principal da dimensão de exploração está nas rotinas que proporcionam às empresas explorar o conhecimento, fornecendo mecanismos estruturais, sistêmicos e processuais que permitem às empresas sustentar a exploração desse conhecimento por longos períodos (Zahra \& George, 2002). Verificou-se nesta pesquisa que a escalabilidade do modelo de negócio das startups, juntamente com a necessidade de atender aos interesses da grande empresa, levou as startups a estruturarem seus processos, desenvolvendo um conjunto profissional, disciplinado e repetível de práticas sobre processos de negócio. Para Zahra e George (2002), os resultados das rotinas de exploração sistemática é a criação persistente de novos bens, sistemas, processos, conhecimento ou novas formas organizacionais. Nesse contexto, observou-se o desenvolvimento de novos produtos e/ou serviços nas startups, mesmo que de forma modesta e incremental.

\section{DISCUSSÃO}

Como uma empresa que está iniciando suas atividades e construindo seu modelo de negócio pode criar vantagens competitivas para sobreviver em um ambiente de negócios dinâmico? Kaplan e Norton (2004) argumentam que a vantagem competitiva de uma empresa surge da criação de valor para o cliente e da exploração e aquisição de recursos existentes, o mesmo indicado por Zahra e George (2002) ao apresentarem o conceito dinâmico de capacidade de absorção. Considerando isso, este estudo busca entender como a capacidade de absorção ocorre nas startups que mantêm relacionamentos interorganizacionais com grandes empresas.

Os resultados mostram que as startups estudadas desenvolvem capacidade de absorver conhecimento da grande empresa, especialmente a capacidade de adquirir e assimilar conhecimento (capacidade de absorção potencial). Isso corrobora o estudo recente de Müller, Buliga \& Voigt (2020), que indica que essa capacidade tem uma relação positiva em empresas nascentes, ou seja, as startups são ativas na aquisição e assimilação de conhecimento externo. A própria estrutura dos programas de aceleração favorece a aquisição do conhecimento externo, visto que está voltada a disponibilizar uma rede de mentores e fornecer capacitações personalizadas às startups, da mesma forma que estimula a internalização e disseminação desse conhecimento (Crișan et al., 2019; Lange \& Johnston, 2020).

A transformação do conhecimento para uso efetivo nas startups está diretamente relacionada à sustentabilidade das relações comerciais mantidas com a grande empresa, seus clientes e/ou parceiros. A transição da capacidade de absorção potencial para realizada materializase nas mudanças significativas que as startups apresentam em sua cultura e gestão empresarial, em parte por estarem em contato direto com os modelos de gestão das grandes empresas e vivenciando sua cultura organizacional. Por outro lado, Müller et al. (2020) sugerem que as startups podem querer se concentrar no desenvolvimento de modelos de negócio centrados em novidades, ao invés de fazer com mais eficiência o que foi feito antes pelas grandes organizações. De fato, apesar de as startups poderem apresentar esse comportamento, também são influenciadas pela cultura corporativa das grandes empresas, que consideram a colaboração entre organizações primordial, incentivando o pensamento multifuncional que promove a aquisição de conhecimentos externos (Müller, Buliga, \& Voigt, 2020). 
As startups envolvidas nos programas de aceleração corporativa apresentam uma forte tendência para inovação organizacional, uma vez que novos processos de gestão empresarial são incorporados às práticas de negócio, implementando novos métodos organizacionais para lidar com a produção de valor para os clientes e stakeholders envolvidos. O Manual de Oslo em sua $4^{\mathrm{a}}$ edição (Organisation for Economic Co-operation and Development [OECD], 2018) explica que a inovação organizacional está contida em um tipo de inovação de processos de negócio, relacionada a funções administrativas e de gerenciamento, incluindo a gestão estratégica e geral dos negócios e o gerenciamento de relacionamentos externos, além de alianças. Evidências demonstraram que as startups se beneficiam, em termos de inovação, quando realizam interações comerciais com outras empresas, obtêm orientação, compartilhamento de experiências e benefícios de programas fomentados por grandes empresas (Sudiana, Sule, Soemaryani, \& Yunizar, 2020).

A análise dos processos que constituem a capacidade de absorção das startups evidenciou a relação entre o constructo capacidade de absorção e o gerenciamento de processos de negócio, em consonância com os estudos de Srivardhana e Pawlowski (2007), Gutiérrez et al. (2012) e Manfreda et al. (2014). As startups inseridas nos programas de aceleração corporativa são levadas a desenvolver rotinas organizacionais específicas e processos que operacionalizam e potencializam a aprendizagem organizacional, da mesma forma que a utilização do conhecimento adquirido externamente, assimilado e transformado proporciona às startups condições para melhoria contínua dos processos de negócio considerados críticos.

Nos programas de aceleração corporativa, não foi evidenciada a habilidade das startups em criar processos para identificar e obter conhecimentos a partir de fontes externas ao programa de aceleração, ou seja, em outras empresas que não sejam as que fomentam diretamente o programa de aceleração. No entanto, são habilidosas em desenvolver processos e rotinas úteis para análise, interpretação, compreensão e disseminação dos conhecimentos adquiridos da empresa parceira. Essas habilidades são referenciadas no trabalho de Flatten et al. (2011), destacando o fluxo de informações e a comunicação efetiva das organizações.

Em decorrência dessa habilidade de processar o conhecimento, as startups são capazes de transformá-lo e aplicá-lo na melhoria do seu desempenho, ou seja, de transformar o conhecimento recém-adaptado e explorá- lo comercialmente, adquirindo vantagem competitiva (Flatten et al., 2011). De fato, as startups conseguem desenvolver novos processos ou alterar os já existentes para atender às necessidades das grandes empresas ou sustentar as relações comerciais existentes, apropriandose do conhecimento absorvido para manter uma vantagem competitiva frente ao mercado.

Os processos de negócio que surgem nos relacionamentos interorganizacionais entre as grandes empresas e startups estão relacionados aos fluxos de informações que são processados pelas empresas nos programas de aceleração. A proximidade geográfica proporcionada pelos programas facilita a troca regular de informações face a face e permite a colaboração em inovação aberta entre as startups e as grandes empresas (Moschner et al., 2019), além de os participantes terem a oportunidade de aprender uns com os outros participando de treinamentos conjuntos ou trocando informações informalmente durante um almoço ou café nas instalações da aceleradora.

O gerenciamento desses processos relacionados aos fluxos de informações, de forma efetiva e sistematizada, emerge nas startups enquanto estão sendo aceleradas e tem um efeito positivo e significativo na implementação e realização da capacidade de absorção. A aprendizagem organizacional gera, nas startups, modificações na forma como realizam suas atividades, provocando mudanças nas rotinas e comportamentos que já estavam estabelecidos. Nesse contexto, as possíveis vantagens competitivas decorrentes da capacidade de absorção concretizam-se nas startups por meio da flexibilidade estratégica, da inovação do tipo organizacional e no desempenho organizacional, refletindo no estabelecimento de certa formalização de seus processos internos.

Dessa forma, com base nos resultados encontrados, a Figura 7 apresenta um modelo de processo que responde à pergunta de pesquisa, apresentada na seção 1 deste artigo, e sintetiza as contribuições do estudo. Vale ressaltar que o modelo de processo teve como base o estudo de Aribi e Dupouët (2016). 


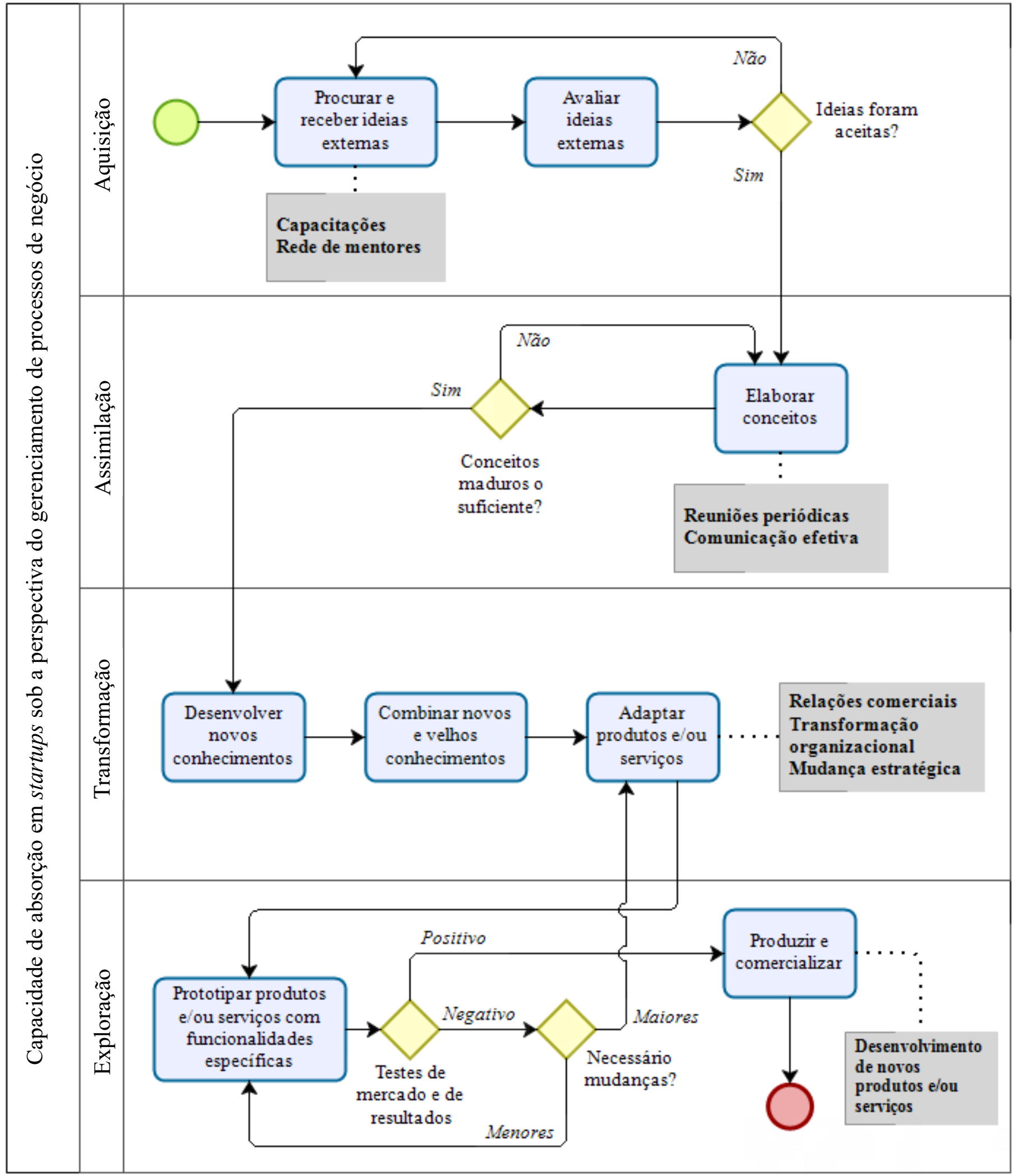

Figura 7. Capacidade de absorção em startups sob a perspectiva do gerenciamento de processos de negócio. 


\section{CONCLUSÕES}

Este estudo fornece uma compreensão sobre a implementação e realização dos processos de negócio que constituem a capacidade de absorção em startups que se relacionam com grandes empresas, por meio de programas de aceleração corporativa. Isso possibilita o avanço do conhecimento na área de capacidades de absorção, em especial a lacuna ainda pouco conhecida de como efetivamente os conceitos dinâmicos de capacidade de absorção (Zahra \& George, 2002) são implementados nas empresas (Aribi \& Dupouët, 2016).

As capacitações promovidas pelas aceleradoras corporativas e a rede de mentores disponibilizada pelas grandes empresas possibilitam acesso a novas ideias, que são posteriormente avaliadas e aceitas ou não pelas startups, o que faz parte da dimensão de aquisição de conhecimento. Já a assimilação de conhecimento engloba o desenvolvimento de conceitos que, possivelmente, serão transformados em novos conhecimentos. Essa etapa é operacionalizada pela realização de reuniões periódicas e uma comunicação efetiva entre os membros das startups e os da grande empresa.

A dimensão de transformação é a modificação dabase deconhecimento tecnológicoe organizacional existente nas startups, gerando produtos e/ou serviços adaptados às necessidades da grande empresa para sustentar as relações comerciais existentes, bem como promovendo transformação organizacional e mudanças estratégicas nas startups. Finalmente, a exploração da base de conhecimento transformado converte-se em novos produtos e/ ou serviços que são introduzidos no mercado, e isso não foi claramente observado nos casos estudados. Quando muito, houve alguma inovação em produtos e serviços que atenderam diretamente à demanda da grande empresa parceira, mas não se observou a exploração do mercado competitivo a partir dessas evoluções. Assim, a inter-relação com a grande empresa numa aceleradora possibilita o desenvolvimento de capacidade de absorção, mas ele não é integral, sendo mais limitado em suas etapas finais (transformação e exploração).

Essa descrição atende ao objetivo do artigo, já que responde como ocorre o processo de desenvolvimento de capacidade de absorção pelas startups e evidencia como as ações formais dos programas de aceleração corporativa de grandes empresas contribuem para isso.

Portanto, conclui-se que a participação de startups em programas de aceleração potencializa o desenvolvimento da capacidade de absorção dessas empresas nascentes, já que facilita o acesso e a assimilação de conhecimento, e consequente transformação de sua base (estrutura, processos e recursos) para atender à grande empresa parceira. No entanto, vale destacar que a exploração comercial não é diretamente beneficiada das ações formais dos programas. Assim, para esses programas estudados, o desenvolvimento de capacidade de absorção potencial é mais claramente observado do que o de absorção realizada.

Por fim, vale considerar que as descobertas apresentadas são de interesse direto das empresas nascentes, que precisam desenvolver capacidades para terem um modelo de negócio competitivo, e podem fazê-lo por meio de parcerias com grandes empresas. Não apenas as startups se beneficiam diretamente dos resultados deste trabalho, mas também as grandes corporações que buscam alianças estratégicas com empresas que estão iniciando suas atividades e pesquisadores interessados em entender a importância dos relacionamentos interorganizacionais para criação de vantagem competitiva.

\section{LIMITAÇÕES DA PESQUISA E TRABALHOS FUTUROS}

As limitações relacionadas ao presente estudo envolvem, num primeiro momento, a adoção do estudo de caso como método qualitativo para a pesquisa de campo, uma vez que os resultados obtidos, mesmo contando com uma combinação de múltiplas fontes de evidências, não podem ser generalizados para outras empresas, restringindose às unidades de análise escolhidas devido às especificidades do contexto.

Ademais, este estudo foi realizado em um período em que as startups estavam inseridas em programas de aceleração corporativa, que favoreceram o desenvolvimento da capacidade de absorção potencial. No entanto, não foi feito um acompanhamento das startups após a saída das aceleradoras, com o objetivo de verificar o desenvolvimento mais efetivo da capacidade de absorção realizada frente ao mercado e manutenção das vantagens competitivas obtidas. Percebe-se nessa limitação uma oportunidade para trabalhos futuros.

\section{NOTA}

${ }^{1}$ Biassociação significa juntar informações não relacionadas, muitas vezes conflitantes, de uma nova maneira (Koestler, 1966, citado por Zahra \& George, 2002). 


\section{REFERENCIAS}

Aribi, A., \& Dupouët, O. (2016). Absorptive capacity: A nonlinear process. Knowledge Management Research and Practice, 14(1), 15-26. https://doi.org/10.1057/ kmrp.2014.17

ASQ Service Quality Division (2016, May 6). SIPOC (suppliers, inputs, process, outputs, customers) diagram. Retrieved from http://asqservicequality.org/glossary/sipocsuppliers-inputs-process-outputs-customers-diagram/

Association of Business Process Management Professionals (2013). Guia para o gerenciamento de processos de negócio: Corpo comum de conhecimento. São Paulo: ABPMP.

Autio, E., George, G., \& Alexy, O. (2011). International entrepreneurship and capability development: Qualitative evidence and future research directions. Entrepreneurship Theory and Practice, 35(1), 11-37. https://doi.org/10.1111/j.1540-6520.2010.00421.x

Bardin, L. (2016). Análise de conteúdo. São Paulo: Edições 70.

Barringer, B. R., \& Harrison, J. S. (2000). Walking a tightrope: Creating value through interorganizational relationships. Journal of Management, 26(3), 367-403. https://doi.org/10.1177/014920630002600302

Bauer, M. W., \& Gaskell, G. (2015). Pesquisa qualitativa com texto, imagem e som: Um manual prático (13a ed.). Petrópolis: Vozes.

Baum, J. A. C., Calabrese, T., \& Silverman, B. S. (2000). Don't go it alone: Alliance network composition and startups' performance in Canadian biotechnology. Strategic Management Journal, 21(3), 267-294. https://doi.org/10.1002/(SICI)10970266(200003)21:3\%3C267::AID-SMJ89\%3E3.0.CO;2-8

Blank, S., \& Dorf, B. (2014). Startup: Manual do empreendedor. Rio de Janeiro: Alta Books.

Burlton, R. (2010). Delivering business strategy through process management. In J. Vom Brocke; M. Rosemann (Eds.). Handbook on business process management: Strategic alignment, governance, people and culture (pp. 5-37, v. 2, part. 1). Berlin: Springer.

Camisón, C., \& Forés, B. (2010). Knowledge absorptive capacity: New insights for its conceptualization and measurement. Journal of Business Research, 63(7), 707715. https://doi.org/10.1016/j.jbusres.2009.04.022

Ceccagnoli, M., Forman, C., Huang, P., \& Wu, D. (2012). Cocreation of value in a platform ecosystem: The case of enterprise software. MIS Quarterly, 36(1), 263-290. https://doi.org/10.2307/41410417

Chaudhary, S., \& Batra, S. (2018). Proposing a sequential operationalization of absorptive capacity. Measuring Business Excellence, 22(1), 64-74. https://doi. org/10.1108/MBE-04-2017-0014

Cohen, W. M., \& Levinthal, D. A. (1990). Absorptive capacity: A new perspective on learning and innovation. Administrative Science Quarterly, 35(1), 128-152. https://doi.org/10.2307/2393553

Crișan, E. L., Salanță, I. I., Beleiu, I. N., Bordean, O. N., \& Bunduchi, R. (2019). A systematic literature review on accelerators. The Journal of Technology Transfer, 1-28. https://doi.org/10.1007/s10961-019-09754-9
Dooley, L., Kenny, B., \& Cronin, M. (2015). Interorganizational innovation across geographic and cognitive boundaries: Does firm size matter? $R \& D$ Management, 46(Supl.), 227-243. https://doi.org/10.1111/radm.12134

Eisenmann, T. R., Parker, G., \& Alstyne, M. V. (2009). Opening platforms: How, when and why? In A. Gawer (Ed.). Platforms, markets and innovation (Chap. 6, pp. 131162), Cheltenham, U.K. and Northampton, MA: Edward Elgar Publishing.

Evangelista, F., \& Mac, L. (2016). The influence of experience and deliberate learning on SME export performance. International Journal of Entrepreneurial Behavior \& Research, 22(6), 860-879. https://doi.org/10.1108/ IJEBR-12-2015-0300

Field, A. (2009). Descobrindo a estatística usando o SPSS (2nd ed.). Porto Alegre: Artmed.

Flatten, T. C., Engelen, A., Zahra, S. A., \& Brettel, M. (2011). A measure of absorptive capacity: Scale development and validation. European Management Journal, 29(2), 98-116. https://doi.org/10.1016/j.emj.2010.11.002

Groote, J. K., \& Backmann, J. (2020). Initiating open innovation collaborations between incumbents and startups: How can David and Goliath get along? International Journal of Innovation Management, 24(2), 2050011. https:// doi.org/10.1142/S1363919620500115

Gutiérrez, L. J. G., Bustinza, O. F., \& Molina, V. B. (2012). Six sigma, absorptive capacity and organisational learning orientation. International Journal of Production Research, 50(3), 661-675. https://doi.org/10.1080/002 07543.2010 .543175

Hindle, T. (2002). Tudo sobre administração. São Paulo: Nobel.

Hoang, H., \& Antoncic, B. (2003). Network-based research in entrepreneurship: A critical review. Journal of Business Venturing, 18(2), 165-187. https://doi.org/10.1016/ S0883-9026(02)00081-2

Hogenhuis, B. N., van den Hende, E. A., \& Hultink, E. J. (2016). When should large firms collaborate with young ventures? Understanding young firms' strengths can help firms make the right decisions around asymmetric collaborations. Research-Technology Management, 59(1), 39-47. https://doi.org/10.1080/08956308.2016 .1117329

Huang, F., Rice, J., \& Martin, N. (2015). Does open innovation apply to China? Exploring the contingent role of external knowledge sources and internal absorptive capacity in Chinese large firms and SMEs. Journal of Management \& Organization, 21(5), 594-613. https://doi.org/10.1017/ jmo.2014.79

Hyytinen, A., Pajarinen, M., \& Rouvinen, P. (2015). Does innovativeness reduce startup survival rates? Journal of Business Venturing, 30(4), 564-581. https://doi. org/10.1016/j.jbusvent.2014.10.001

Ireland, R. D., Hitt, M. A., \& Vaidyanath, D. (2002). Alliance management as a source of competitive advantage. Journal of Management, 28(3), 413-446. https://doi. org/10.1016/S0149-2063(02)00134-4

Jang, H., Lee, K., \& Yoon, B. (2017). Development of an open innovation model for R\&D collaboration between large firms and small-medium enterprises (SMES) in manufacturing industries. International Journal of Innovation Management, 21(1), 1750002. https://doi. org/10.1142/S1363919617500025 
Jiménez-Barrionuevo, M. M., García-Morales, V. J., \& Molina, L. M. (2011). Validation of an instrument to measure absorptive capacity. Technovation, 31(5-6), 190-202. https://doi.org/10.1016/j.technovation.2010.12.002

Kaplan, R. S., \& Norton, D. P. (2004). Strategy maps: Converting intangible assets into tangible outcomes. Boston: Harvard Business School Press.

Kato, M. (2020). Founders' human capital and external knowledge sourcing: Exploring the absorptive capacity of start-up firms. Economics of Innovation and New Technology, 29(2), 184-205. https://doi.org/10.1080/ 10438599.2019 .1598670

Lange, G. S., \& Johnston, W. J. (2020). The value of business accelerators and incubators-an entrepreneur's perspective. Journal of Business \& Industrial Marketing. Advance online publication. https://doi.org/10.1108/ JBIM-01-2019-0024

Lewin, A. Y., Massini, S., \& Peeters, C. (2011). Microfoundations of internal and external absorptive capacity routines. Organization Science, 22(1), 81-98. https://doi. org/10.1287/orsc. 1100.0525

Ma, X., Zhou, Z., \& Fan, X. (2015). The process of dynamic capability emergence in technology start-ups: An exploratory longitudinal study in China. Technology Analysis \& Strategic Management, 27(6), 675-692. https://doi.org/10.1080/09537325.2015.1034266

Manfreda, A., Kovacic, A., Štemberger, M. I., \& Trkman, P. (2014). Absorptive capacity as a precondition for business process improvement. Journal of Computer Information Systems, 54(2), 35-43. https://doi.org/10. $1080 / 08874417.2014 .11645684$

Moschner, S.-L., Fink, A. A., Kurpjuweit, S., Wagner, S. M., \& Herstatt, C. (2019). Toward a better understanding of corporate accelerator models. Business Horizons, 62(5), 637-647. https://doi.org/10.1016/j. bushor.2019.05.006

Müller, J. M., Buliga, O., \& Voigt, K. I. (2020). The role of absorptive capacity and innovation strategy in the design of industry 4.0 business Models: A comparison between SMEs and large enterprises. European Management Journal. Advance online publication. https://doi.org/10.1016/j.emj.2020.01.002

Pavlou, P. A., \& El Sawy, O. A. (2006). From IT leveraging competence to competitive advantage in turbulent environments: The case of new product development. Information Systems Research, 17(3), 198-227. https:// doi.org/10.1287/isre.1060.0094

Organisation for Economic Co-operation and Development. (2018). Oslo manual 2018: Guidelines for collecting, reporting and using data on innovation (4th ed.). Paris: Organisation for Economic Co-operation and Development (OECD).

Rodríguez-Serrano, M. Á., \& Martín-Armario, E. (2019). Bornglobal SMEs, performance, and dynamic absorptive capacity: Evidence from Spanish firms. Journal of Small Business Management, 57(2), 298-326. https:// doi.org/10.1111/jsbm.12319
Sampieri, R. H., Collado, C. F., \& Lucio, M. del P. B. (2013). Metodologia de pesquisa (5th ed.). Porto Alegre: Penso.

Savarese, M. F., Orsi, L., \& Belussi, F. (2016). New venture high growth in high-tech environments. European Planning Studies, 24(11), 1937-1958. https://doi.org/10.1080/0 9654313.2016 .1232700

Schilke, O., Hu, S., \& Helfat, C. E. (2018). Quo vadis, dynamic capabilities? A content-analytic review of the current state of knowledge and recommendations for future research. Academy of Management Annals, 12(1), 390439. https://doi.org/10.5465/annals.2016.0014

Shankar, R. K., \& Shepherd, D. A. (2019). Accelerating strategic fit or venture emergence: Different paths adopted by corporate accelerators. Journal of Business Venturing, 34(5), 105886. https://doi.org/10.1016/j. jbusvent.2018.06.004

Srivardhana, T., \& Pawlowski, S. D. (2007). ERP systems as an enabler of sustained business process innovation: A knowledge-based view. The Journal of Strategic Information Systems, 16(1), 51-69. https://doi. org/10.1016/j.jsis.2007.01.003

Stuart, T. E. (2000). Interorganizational alliances and the performance of firms: A study of growth and innovation rates in a high-technology industry. Strategic Management Journal, 21(8), 791-811. https://doi. org/10.1002/1097-0266(200008)21:8<791::AIDSMJ121>3.0.CO;2-K

Sudiana, K., Sule, E. T., Soemaryani, I., \& Yunizar, Y. (2020). The development and validation of the penta helix construct. Business: Theory and Practice, 21(1), 136145. https://doi.org/10.3846/btp.2020.11231

Teece, D. J., Pisano, G., \& Shuen, A. (1997). Dynamic capabilities and strategic management. Strategic Management Journal, 18(7), 509-533. https://doi. org/10.1002/(SICI)1097-0266(199708)18:7<509::AIDSMJ882>3.0.CO;2-Z

Tidd, J., Bessant, J., \& Pavitt, K. (2008). Gestão da inovação (3rd ed.). Porto Alegre Bookman.

Urbaniec, M., \& Żur, A. (2020). Business model innovation in corporate entrepreneurship: Exploratory insights from corporate accelerators. International Entrepreneurship and Management Journal, 1-24. https://doi. org/10.1007/s11365-020-00646-1

Weiblen, T., \& Chesbrough, H. W. (2015). Engaging with startups to enhance corporate innovation. California Management Review, 57(2), 66-90. https://doi. org/10.1525/cmr.2015.57.2.66

Wasiuzzaman, S. (2019). Resource sharing in interfirm alliances between SMEs and large firms and SME access to finance: A study of Malaysian SMEs. Management Research Review, 42(12), 1375-1399. https://doi. org/10.1108/MRR-10-2018-0369

Yin, R. K. (2015). Estudo de caso: Planejamento e métodos (5th ed.). Porto Alegre: Bookman.

Zahra, S. A., \& George, G. (2002). Absorptive capacity: A review, reconceptualization, and extension. Academy of Management Review, 27(2), 185-203. https://doi. org/10.5465/AMR.2002.6587995 


\section{Autoria}

\section{Alexandre Rodrigues Cajuela*}

Av. Bandeirantes, $n^{0}$ 3900, Vila Monte Alegre, 14040-905, Ribeirão Preto, SP, Brasil.

E-mail: alexandrecajuela@usp.br

(1) https://orcid.org/0000-0002-9836-8676

\section{Simone Vasconcelos Ribeiro Galina}

Av. Bandeirantes, $\mathrm{n}^{0}$ 3900, Vila Monte Alegre, 14040-905 , Ribeirão Preto, SP, Brasil.

E-mail: svgalina@usp.br

(1) https://orcid.org/0000-0001-7150-2217

* Autor Correspondente

\section{Contribuições dos Autores}

10 autor: conceituação (liderança); curadoria de dados (liderança); análise formal (liderança); investigação (liderança); metodologia (liderança); administração do projeto (igual); software (liderança); supervisão (igual); validação (igual); visualização (igual); escrita - rascunho original (liderança); escrita - revisão e edição (igual).

$2^{\mathbf{a}}$ autora: conceituação (suporte); curadoria de dados (suporte); análise formal (suporte); investigação (suporte); metodologia (suporte); administração de projeto (igual); software (suporte); supervisão (igual); validação (igual); visualização (igual); escrita - rascunho original (suporte); escrita - revisão e edição (igual).

\section{Financiamento}

Os autores informaram que não houve apoio financeiro para a pesquisa neste artigo.

\section{Conflito de Interesses}

Os autores informaram que não há conflito de interesses.

\section{Direitos Autorais}

A RAC detém os direitos autorais deste conteúdo.

\section{Verificação de Plágio}

A RAC mantém a prática de submeter todos os documentos aprovados para publicação à verificação de plágio, mediante o emprego de ferramentas específicas, e.g.: iThenticate.

\section{Método de Revisão por Pares}

Este conteúdo foi avaliado utilizando o processo de revisão por pares duplo-cego (double-blind peer-review). A divulgação das informações dos pareceristas constantes na primeira página é feita somente após a conclusão do processo avaliativo, e com o consentimento voluntário dos respectivos pareceristas.

\section{Disponibilidade dos Dados}

Todos os dados e materiais foram disponibilizados publicamente por meio da plataforma Mendeley e podem ser acessados em:

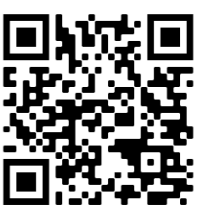

Cajuela, Alexandre; Galina, Simone (2020), “Data for "Processes in interorganizational relationships to develop absorptive capacity in startups" published by RAC - Revista de Administração Contemporânea", Mendeley Data, v1. http://dx.doi.org/10.17632/pdyvchky3c.1

A RAC incentiva o compartilhamento de dados mas, por observância a ditames éticos, não demanda a divulgação de qualquer meio de identificação de sujeitos de pesquisa, preservando a privacidade dos sujeitos de pesquisa. A prática de open data é viabilizar a reproducibilidade de resultados, e assegurar a irrestrita transparência dos resultados da pesquisa publicada, sem que seja demandada a identidade de sujeitos de pesquisa. 